PREPARED FOR THE U.S. DEPARTMENT OF ENERGY, UNDER CONTRACT DE-AC02-76CH03073

PPPL-3939

PPPL-3939

UC-70

Optimization of Outer Poloidal Field (PF) Coil Configurations

for Inductive PF Coil-only Plasma Start-up

on Spherical Tori

by

Wonho Choe, Jayhyun Kim, and Masayuki Ono

April 2004

$N_{\substack{\text { PRInCETOn PLASMA } \\ \text { PHYSIES LABORATORY }}}^{D}$

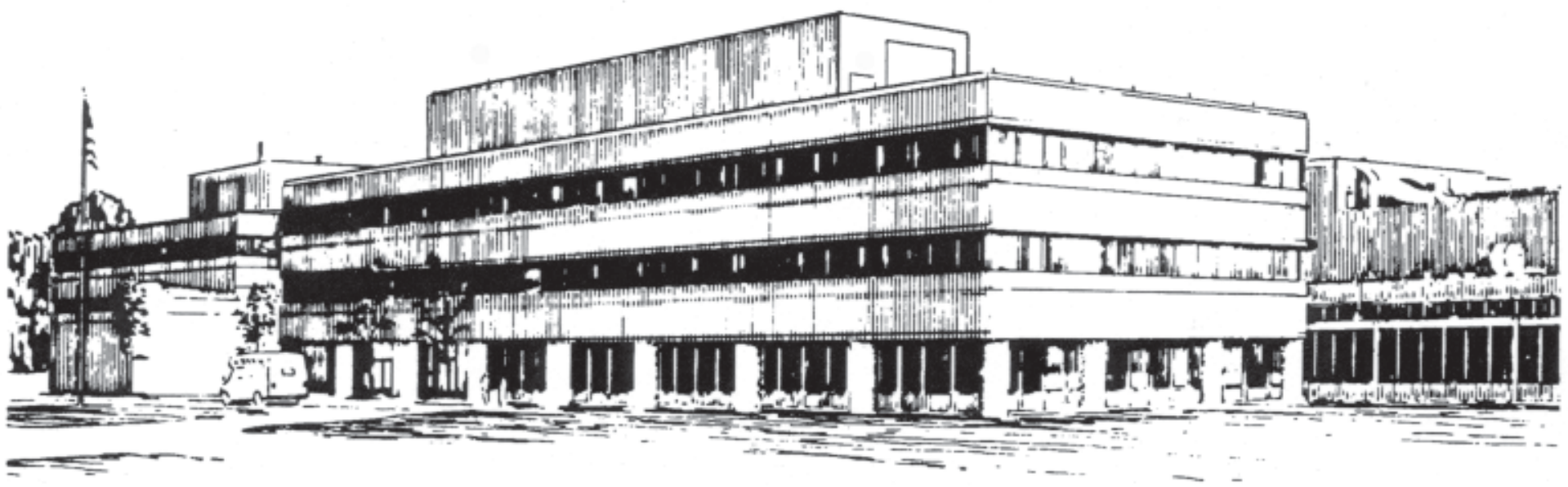

PRINCETON PLASMA PHYSICS LABORATORY PRINCETON UNIVERSITY, PRINCETON, NEW JERSEY 


\section{PPPL Reports Disclaimer}

This report was prepared as an account of work sponsored by an agency of the United States Government. Neither the United States Government nor any agency thereof, nor any of their employees, makes any warranty, express or implied, or assumes any legal liability or responsibility for the accuracy, completeness, or usefulness of any information, apparatus, product, or process disclosed, or represents that its use would not infringe privately owned rights. Reference herein to any specific commercial product, process, or service by trade name, trademark, manufacturer, or otherwise, does not necessarily constitute or imply its endorsement, recommendation, or favoring by the United States Government or any agency thereof. The views and opinions of authors expressed herein do not necessarily state or reflect those of the United States Government or any agency thereof.

\section{Availability}

This report is posted on the U.S. Department of Energy's Princeton Plasma Physics Laboratory Publications and Reports web site in Fiscal Year 2004. The home page for PPPL Reports and Publications is: http://www.pppl.gov/pub_report/

DOE and DOE Contractors can obtain copies of this report from:

U.S. Department of Energy

Office of Scientific and Technical Information

DOE Technical Information Services (DTIS)

P.O. Box 62

Oak Ridge, TN 37831

Telephone: (865) 576-8401

Fax: (865) 576-5728

Email: reports@adonis.osti.gov

This report is available to the general public from:

National Technical Information Service

U.S. Department of Commerce

5285 Port Royal Road

Springfield, VA 22161

Telephone: $1-800-553-6847$ or

(703) $605-6000$

Fax: (703) 321-8547

Internet: http://www.ntis.gov/ordering.htm 


\title{
OPTIMIZATION OF OUTER POLOIDAL FIELD (PF) COIL CONFIGURATIONS FOR INDUCTIVE PF COIL-ONLY PLASMA START-UP ON SPHERICAL TORI
}

\author{
WONHO CHOE, JAYHYUN KIM Department of Physics, Korea Advanced Institute of Science \\ and Technology, 373-1 Guseong-dong, Yuseong-gu, Daejeon 305-701, Korea
}

MASAYUKI ONO Princeton Plasma Physics Laboratory, Princeton University, New Jersey 08540, USA

The elimination of in-board ohmic heating solenoid is required for the spherical torus (ST) to function as an attractive fusion power plant. An in-board ohmic solenoid, along with the shielding needed for its insulation, increases the size and, hence, the cost of the plant. Here, we investigate using static as well as dynamic codes in ST geometries a solenoid-free start-up concept utilizing a set of out-board poloidal field coils. By using the static code, an optimization of coil positions as well as coil currents was performed to demonstrate that it is indeed possible to create a high quality multi-pole field null region while retaining significant flux (volt-seconds) needed for the subsequent current ramp-up. With the dynamic code which includes the effect of vacuum vessel eddy currents, we then showed that it is possible to maintain a large size field null region for several milliseconds in which sufficient ionization avalanche can develop in the applied toroidal electric field. Under the magnetic geometry typical of a next generation spherical torus experiment, it is shown that the well-known plasma breakdown conditions for conventional ohmic solenoid start-up of $\mathrm{E}_{\mathrm{T}} \mathrm{B}_{\mathrm{T}} / \mathrm{B}_{\mathrm{P}} \sim(0.1-1) \mathrm{kV} / \mathrm{m}$ with $\mathrm{V}_{\text {loop }} \sim 6 \mathrm{~V}$ can be readily met while retaining significant volt-seconds $\sim 4 \mathrm{~V}$-S sufficient to generate multi-MA plasma current in STs.

KEYWORDS: start-up, spherical torus, poloidal field coil, inductive 


\section{INTRODUCTION}

In the fusion research conducted worldwide, the ohmic heating solenoid has been commonly used to start-up tokamak, spherical torus (ST) [1], and other toroidal plasmas aiming to develop an attractive fusion power source. A conventional ohmic solenoid is placed in the in-board side of the toroidal plasma and, as the one shown in Fig. 1, it produces a very large vertical field (i.e., poloidal magnetic flux) inside the ohmic coil and essentially zero field outside the solenoid or inside the plasma region. This property makes it well suited to initiate a toroidal plasma current by magnetic induction since the plasma initiation usually requires very small transverse stray field.

However, looking toward attractive/economical fusion power plants, the in-board ohmic solenoid places a high premium on the cost of the plant. An in-board ohmic solenoid, along with the shielding needed for its insulation, increases the size and, hence, the cost of the plant. This problem tends to become increasingly severe as the plasma aspect ratio $\mathrm{R} / \mathrm{a}$ is reduced toward unity, where " $\mathrm{R}$ " and " $\mathrm{a}$ " denotes major radius and minor radius, respectively. As can be seen from Fig. 1, the in-board region shrinks in size as $\mathrm{R} / \mathrm{a}$ is decreased. The problem is particularly challenging for the ST reactors where the aspect ratio is typically of the order of 1.5 which means that the available inboard radial space is only half that of the plasma minor radius. This tight space would make the placement of ohmic solenoid, and related neutron shielding and blanket impractical. Indeed, ST-based fusion systems including the CTF (Component Test Facility) [2] and power plant designs (e.g., ARIES-ST [3]) assume complete elimination of the ohmic solenoid. It is worthwhile to note that the designs for much higher aspectratio advanced tokamak reactors such as the ARIES-AT [4] also assume no inboard solenoid. At the present time, however, the plasma start-up without an ohmic solenoid for tokamak/ST reactors remains challenging.

The non-inductive start-up and current ramp-up methods utilizing radio frequency and NBI (neutral beam injection) current drive have been successfully demonstrated on various devices but at sub-mega-ampere level [5,6,7]. The bootstrap current over-drive based ramp-up is also identified as a promising current ramp-up technique in reactor designs where the very long ramp-up time requirement is not an inherent issue for a 
steady-state reactor system. A method based on coaxial helicity injection (CHI) [8] has been successfully demonstrated on spheromaks and smaller ST devices. It is now being tested on NSTX at about 0.5 MA level. However, these methods are generally plasma physics intensive that a considerable physics R\&D effort will be required to extend these techniques toward multi-MA regimes needed for the next generation devices.

The inductive variances of plasma start-up without ohmic solenoid are also being pursued at sub-mega-ampere level with some successes. The MAST experiment routinely uses poloidal field coils at a larger major radius than the plasma but still inside the vacuum vessel to initiate the plasma and ramping up the plasma current by merging/compression process [9]. This approach could however limit the horizontal midplane access needed, for example, for the removable blanket module for CTF.

It has been also suggested that plasma heating and associated vertical field rampup can provide an efficient means of plasma current ramp-up. Inductive plasma current start-up can be induced by outer vertical field coils with the help of the strong heating power and with the small central solenoid flux for flux waveform adjustment [10] or without the $\mathrm{OH}$ transformer [11]. However, the TSC simulation suggests that it may not be practical to ramp-up plasma current solely by vertical field though the vertical field provides a significant fraction ( 1/3) of needed flux for current ramp-up [12].

Recently, JT-60U has demonstrated generation of $200 \mathrm{kA}$ of plasma current by outer PF coil induction without using ohmic solenoid [13]. Strong rf preionization was used to help initiate the plasma. In this experiment, a part of the vertical field coils called VT coil set in the device had a pair of in-board side turns, and it was also energized to provide magnetic flux during the breakdown avalanche and the initial current drive. For an ST reactor, however, no poloidal field coils are envisioned in the in-board side. There are also ideas of using compact torus (CT) merging to create STs as demonstrated in the TS-3 device [14]. However, this concept thus far requires internal coils to initiate plasma formation.

\section{BASIC CONCEPT OF THE OUT-BOARD OHMIC INDUCTION UTILIZING OUTER POLOIDAL FIELD COIL SYSTEM}


A basic schematic of the solenoid-free concept utilizing a set of poloidal field (PF) coils placed in the out-board region of the plasma [15] is shown in Fig. 2. As will be shown, the spherical torus geometry offers a configurational flexibility for the PF coil placement to produce a good quality field null while retaining significant poloidal field flux. The present out-board ohmic induction coil system tries to mimic the solenoidal ohmic induction property for a limited volume as indicated in Fig. 2(b) as the initial plasma start-up region. In this volume, the transverse stray magnetic field can be made to a small value, which will be shown in the model calculation in the following section. The present out-board ohmic induction coil consists of three basic types of poloidal field coils labeled \#1, \#2, and \#3 although one can make further improvements using more number of coils. In this exercise, we assume the coils to be up and down symmetric with respect to mid-plane, thus the radial field component is zero at the mid-plane by symmetry. The shaded region for each coil, as shown in Fig. 2(b), represents a general area of placement for the coil.

Here, we first give a qualitative description of how one can produce such a field null using only three types of outboard PF coils labeled \#1, \#2, and \#3. The small-radius Coil \#1 placed at a small solid angle $\phi$ (with respect to the major axis) produces a vertical field at the mid-plane that peaks at the major axis and decreases toward larger R. The larger diameter Coil \#2 placed near $\phi \sim 45^{\circ}$ produces a nearly uniform Helmholtz-type vertical field at the mid-plane. The vertical field produced by Coil \#3 placed near the mid-plane $\left(\phi \sim 90^{\circ}\right)$ actually increases with $\mathrm{R}$ at larger R. By properly combining those three types of vertical fields, it is possible to create a high quality field null in the shaded region in Fig. 3(a). If the fields produced by Coils \#1 and \#3 are added, the resulting field is peaked at the major axis which decreases with $\mathrm{R}$, but the field gradient can be made to be small near the null region since the field gradients for Coil \#1 and \#3 are opposite as shown in Fig. 3(b). It is then possible to position Coil \#2 to produce an appropriate gradient to cancel the small gradient produced by the combined Coils \#1 and \#3 fields. The position and field of Coil \#2 can be adjusted to create a good quality field null (zero field) region which also has zero field gradients (at least zero values for the first and second derivatives) as shown in Fig. 3(b). It is possible to make the higher order gradient zero by careful choices of coil positions and currents as shown in the numerical 
model below. By using more number of "trim" coils, one can further increase the quality of null if needed. The magnetic induction flux available for the current ramp up is the amount of vertical field flux going through the area encircled by the plasma minor axis of fully developed plasma as depicted in Fig. 3(c). Since the Coil \#2 generates generally uniform field, there is a significant net flux left over in the inner region due primarily to the peaked profile produced by Coil \#1. Once the plasma initiates at the null field region, the plasma current can be ramped up by utilizing the available poloidal flux (i.e., voltseconds) by ramping down the poloidal field coil currents. As the plasma current ramps up, the plasma size increases and the plasma position can be gradually shifted toward the final position by a feed back control.

\section{CONFIGURATION OPTIMIZATION}

In order to give an accurate picture of how this out-board ohmic induction coil system actually works, a numerical modeling was performed for the next step spherical torus (NSST) [16] geometry. In this exercise, we restricted the coil placement to be outside the NSST vacuum vessel as shown in Fig. 4. The numerical code used for the static vacuum field modeling seeks the optimal PF coil currents for producing field null at a given location. The condition to be met for null formation is that the first, second, and third derivative of flux $\psi$ with respect to the major radial coordinate R vanish, i.e., $\mathrm{d} \psi / \mathrm{dR}$ $=\mathrm{d}^{2} \psi / \mathrm{dR}^{2}=\mathrm{d}^{3} \psi / \mathrm{dR}^{3}=0$, at the given location in the case of total five PF coils involved. If $\mathrm{R}=\mathrm{R}^{*}$ is the desired location of the field null, the total magnetic flux $\psi$ can be written as $\psi\left(R^{*}\right)=\sum_{i=1}^{5} \sum_{j=1}^{N_{i}} w_{i j} I_{i} G\left(R^{*}, R_{i j}\right)$ where $G$ is the Green's function, $I_{i}$ is the current of the $i$ th coil, $N_{i}$ is the number of segments in the $i$ th coil, $w_{i j}$ is the number of turns in the $j$ th segment of the $i$ th coil, and $R_{i j}$ is the major radius of the coil segment. Then, the equations to be solved become

$$
\left.\sum_{i} \sum_{j} w_{i j} I_{i} \frac{\partial G}{\partial R}\right|_{R=R^{*}}=\left.\sum_{i} \sum_{j} w_{i j} I_{i} \frac{\partial^{2} G}{\partial R^{2}}\right|_{R=R^{*}}=\left.\sum_{i} \sum_{j} w_{i j} I_{i} \frac{\partial^{3} G}{\partial R^{3}}\right|_{R=R^{*}}=0,
$$

which can be expressed, after a straightforward arrangement, in the form of 


$$
\left(\begin{array}{l}
I_{3} \\
I_{4} \\
I_{5}
\end{array}\right)=-\left(A^{-1} \cdot \underline{\underline{B}}\left(\begin{array}{l}
I_{1} \\
I_{2}
\end{array}\right),\right.
$$

where $\underline{\underline{A}}$ and $\underline{\underline{B}}$ are $3 \times 3$ and $3 \times 2$ matrix, respectively, consisting of the derivatives of the Green's function. Therefore, once two coil currents are prescribed it is possible to find the current of the other three coils that satisfy the constraints. For the case of four coils, only one current is required to satisfy the constraints. That of course assumes that Eq. (1) describes three linearly independent equations. This is the basic reason that the coils must be of sufficiently different types to make these equations sufficiently linearly independent to yield interesting solutions. One should also note that a careful choice of the coil location is also quite important since the coil position can affect the higher order gradients. In the code, an algorithm was utilized to scan the coil position such as the coil \#2 to search for an optimize condition.

The plasma axis of NSST at the full plasma parameters is near $\mathrm{R}=1.75 \mathrm{~m}$. The shaded region in Fig. 4 represents a fully developed plasma for indicating its relative location from coils and vacuum vessel. A nominal out-board mid-plane vacuum vessel location is $3.0 \mathrm{~m}$. In this exercise, the plasma null formation is chosen to start at $\mathrm{R}=2.5$ $\mathrm{m}$ which allows sufficient separation from the vacuum chamber located at $3.0 \mathrm{~m}$. In Fig. 5(a), the vertical field profile is plotted that is generated at the mid-plane by each coil set as labeled. The Coil \#1 is located at $\mathrm{R}=2.0 \mathrm{~m}$ and $\mathrm{Z}= \pm 3.1 \mathrm{~m}$ with $16.0 \mathrm{MA}$-turn. The mid-plane vertical field generated by this coil set is shown in Fig. 5(a), which peaks at $R$ $=0.0 \mathrm{~m}$ (at the major axis) and decreases toward larger $\mathrm{R}$. The Coil \#2 is located at $\mathrm{R}=$ $3.8 \mathrm{~m}$ and $\mathrm{Z}= \pm 1.4 \mathrm{~m}$ with $-6.3 \mathrm{MA}$-turn. The Coil \#2 is essentially a Helmholtz-type coil set that generates relatively flat field profile as shown in the figure. The trim coil set $\# 3$ is located at $R=3.2 \mathrm{~m}$ and $\mathrm{Z}= \pm 0.5 \mathrm{~m}$ with about $2 \mathrm{MA}$-turn. The $\mathrm{R}=3.2 \mathrm{~m}$ location is chosen to be outside the vacuum vessel and the vertical separation between the up and down Coil \#3 of about $1 \mathrm{~m}$ allows the neutral beam injection (NBI) access. The Coil \#3 is still nearly $0.7 \mathrm{~m}$ radially outward from the field null plasma initiation point. It is instructive to add the field generated by Coils \#1 and \#3 as shown in Fig. 5(b). The combination of Coils \#1 and \#3 generates vertical field that has a reduced gradient region around $\mathrm{R}=2.5 \mathrm{~m}$. The field generated by Coil \#2 is also shown. As is seen in Fig. 5(b), 
the fields generated by Coils $\# 1+\# 3$ and \#2 matches very well in the null field region. The resulting net vertical field is plotted in Fig. 5(c), where one can see that the vertical field as well as the gradient values go to zero near $\mathrm{R}=2.5 \mathrm{~m}$.

Figures 5(d) and 5(e) depict the resulting 2-D flux contours and mod-B contours. As can be seen in Fig. 5(d), the null field created is relatively high quality field null with high multiple (eight-fold) poles considered to be desirable for the start-up. This multipole field null configuration helps to initiate relatively stable plasmas although some degree of feedback control is likely to be needed as the plasma current ramps up for plasma position control. The corresponding mod-B contours shown in Fig. 5(e) where the field null region of less than $20 \mathrm{G}$ of $20 \mathrm{~cm}$ diameter is created. The net vertical field in the inner plasma radius $(\mathrm{R} \leq 1.75 \mathrm{~m})$ contributes to the magnetic flux available for the current ramp-up. From Fig. 5(f), about $3.3 \mathrm{~Wb}$ (at $\mathrm{R}=1.75 \mathrm{~m}$ ) is available for the current ramp-up for this particular set of coil currents.

The loop voltage for plasma breakdown and current ramp-up can be induced by ramping down the currents in Coils \#1 to \#3 simultaneously at an appropriate rate. It is shown in Fig. 5(c) that the net vertical field at $R>2.8 \mathrm{~m}$ is negative which is radially stabilizing. This is due to Coil $\# 2$ of which current flows in the direction opposite to the expected plasma current, which indicates that Coil \#2 provides part of the vertical field needed for plasma current radial position stabilization. This may suggest that the rampdown rate for the Coil \#2 current could be slower than those of Coils \#1 and \#3 to generate an appropriate net stabilizing vertical field. Including the effect of additional flux from the equilibrium field coils, the available flux of about $5 \mathrm{~Wb}$ for the NSST case should be sufficient to ramp up the plasma current of a few MA range in NSST. The dynamic calculation results with wall eddy currents will be discussed below.

In Fig. 6, examples of the plasma equilibrium for various values of plasma current are shown. As shown in Fig. 6(a), the initial plasma current begins to flow in the field null region. As the plasma current increases, the plasma size and shaping increases as depicted in Fig. 6(b) and (c). While the null field thus created should satisfy the requirement of breakdown at $5 \mathrm{~V}$ for $\mathrm{B}_{\mathrm{T}}>1 \mathrm{~T}$ with an application of small electron cyclotron heating $(\mathrm{ECH})$ power for pre-ionization as performed routinely for NSTX (National Spherical Torus Experiment) and other devices. 
In the following, we shall give examples from several cases where different combination of coil locations were attempted using the same principle for accommodating various device requirements such as sufficient neutral beam injection and/or blanket access or higher flux attainment. For all cases, we assume the same Coil \#1 current of 16.0 MA-turn. Figure 7 shows the case in which separation between updown Coil \#1 is reduced toward mid-plane compared to the Case I for producing more magnetic flux (Case II). The vacuum vessel shape is changed to better conform to the plasma shape which would also allows the new coil location. As shown in the figure, simply lowering Coil \#1 by $0.5 \mathrm{~m}$ would result in a significant flux increase from $3.3 \mathrm{~Wb}$ to $5.2 \mathrm{~Wb}$ at $\mathrm{R}=1.75 \mathrm{~m}$ and $\mathrm{Z}=0 \mathrm{~m}$ with similar flux and mod-B contours. The position and current values of each coil are found in Table 1.

While the $1.0 \mathrm{~m}$ separation between the up-down Coil \#3 would allow the NBI port access, an attempt was made by placing Coil \#3 on mid-plane with other coils unchanged hoping for utilizing the space between Coils \#2 and \#3 (Case III). Similar quality field null and flux value were obtained as shown in Fig. 8, where the radial profile of vertical field by each coil, the net vertical field, and flux are depicted. In this configuration, Coil \#3 consists of two independent coils \#3_1 and \#3_2 with opposite current polarity, i.e., the direction of Coil \#3_1 current is opposite to that of Coil \#3_2 [Fig. 8(d)] in such a way that the sum of the fields cancels the net field generated by Coils $\# 1$ and \#2. As depicted in Fig. 8(e), the sum of the vertical fields by Coils \#3_1 and \#3_2 located on mid-plane is qualitatively very similar to the case with a pair of up-down Coil \#3 in Fig. 5(a).

Figure 9 shows the case in which the vertical separation between the upper and lower Coil \#2 was increased by $1.0 \mathrm{~m}$ compared to the case in Fig. 8 to provide additional horizontal access such as for the blanket module (Case IV). In this case, the available magnetic flux is only slightly reduced compared to the Case III while the field geometry remains similar.

The space around the out-board-side mid-plane is valuable for hosting various diagnostics, NBI, and/or blanket access, and the placement of coils at the mid-plane can be avoided by a further variation from Fig. 9. Instead of using two coils \#3_1 and \#3_2 on mid-plane, another possible configuration utilizing two pairs of Coil \#3_1 and \#3_2 
that are located away from the mid-plane is shown in Fig. 10 which can generate the similar field profile (Case V). Although the detailed vertical field profile produced by the individual Coil \#3_1 and \#3_2 is different [Fig. 8(d) vs. Fig. 10(e)], the sum of the fields by Coil \#3_1 and \#3_2 shows similarity [Fig. 8(e) vs. Fig. 10(f)]. The available poloidal flux and field null quality are also similar. Since this configuration can still provide significant amount of flux of $4.5 \mathrm{~Wb}$ and offers excellent out-board mid-plane access of about $1.8 \mathrm{~m}$ vertical spacing, this configuration seems to be particularly suitable for the interchangeable blanket modules for a compact ST-based CTF.

The Case I to Case V discussed above demonstrate the flexibility of the solenoidfree out-board PF coil-only induction concept. Various combinations of coil locations with proper alignment of transverse fields allow generation of high quality field null at a desired position with a few $\mathrm{Wb}$ of flux, which will be sufficient for ramping the plasma current up to multi-MA level. The detailed coil locations, current values, and the resulting magnetic flux of each case are summarized in Table. 1.

\section{DEMONSTRATION OF BREAK-DOWN CONDITION WITH DYNAMIC NUMERICAL CODE}

In order to guarantee a successful initial plasma start-up, field null should be maintained for a sufficient period of time or breakdown time, which is often defined as the time taken to reach $50 \%$ ionization of the initially pre-filled gas [17]. In many previous experiments, it corresponds to the time at which the D-alpha emission reached maximum and is typically a few milliseconds in most of the large-size toroidal devices. The sustainment of the field null for the breakdown period requires a time-dependent calculation because the transverse stray field is generated not only by the currents flowing in active coils but also by the eddy currents induced in various passive conductors such as vacuum vessel, passive stabilizer, and other structural materials due to the rapidly changing coil currents during the period. Through the dynamic calculation, a proper waveform of each coil can be obtained which sustains the field null for a sufficient time with a significant amount of magnetic flux required for subsequent plasma current rampup. The time-dependent numerical code used for the modeling solves the coupled circuit equations including terms of vacuum vessel eddy currents in order to search for an 
appropriate set of the PF current waveforms that produces and sustains a quality field null for several milliseconds. The circuit equations were solved by the combination of the eigenmode expansion method [18] and the singular value decomposition method for optimization [19]. During the optimization procedure of the solutions, several constraints (magnitude of loop voltage and flux, radial derivatives of vertical field) were satisfied for the field null generation at the desired location. In addition, current, voltage, and temperature limit of the PF coils were also considered to find the optimized solution set. Detailed description of the numerical modeling will be reported elsewhere.

Figure 11 illustrates an example of the dynamic vacuum field modeling. Coil currents with the waveforms shown in Fig. 11(a) produce the field null by the combined effects of currents in the PF coils and the induced currents in the machine structure from $1.0 \mathrm{~s}$ for more than $10 \mathrm{~ms}$. The corresponding loop voltage is more than $7 \mathrm{~V}$ [Fig. 11(b)]. The condition for highly reliable ohmic induction breakdown can be expressed as $\mathrm{E}_{\mathrm{T}} \cdot \mathrm{B}_{\mathrm{T}} / \mathrm{B}_{\mathrm{P}}>\sim 1 \mathrm{kV} / \mathrm{m}$, where $\mathrm{E}_{\mathrm{T}}$ is the induced toroidal electric field, $\mathrm{B}_{\mathrm{T}}$ is the toroidal magnetic field and $\mathrm{B}_{\mathrm{P}}$ is the average poloidal (i.e. transverse) magnetic field [17]. However, an application of suitable pre-ionization radio-frequency (rf) waves can relax this condition. For example, on DIII-D, operating at $\mathrm{B}_{\mathrm{T}}=2 \mathrm{~T}$, with high-power $(\sim 800$ $\mathrm{kW}) \mathrm{ECH}$ pre-ionization, a successful plasma initiation was achieved at $\mathrm{E}_{\mathrm{T}}=0.3 \mathrm{~V} / \mathrm{m}$ with $\mathrm{B}_{\mathrm{P}}>5 \mathrm{mT}$ over most of the vessel cross-section [17]. This represents a value of $\mathrm{E}_{\mathrm{T}} \cdot \mathrm{B}_{\mathrm{T}} / \mathrm{B}_{\mathrm{P}} \approx 0.12 \mathrm{kV} / \mathrm{m}$. Also in the experiment, the high power $\mathrm{ECH}$ pre-ionization was able to shorten this process to about $2 \mathrm{~ms}$ even with low loop voltage of a few volts. In Figure $11(\mathrm{~d})$, we show the contour of $\mathrm{E}_{\mathrm{T}} \cdot \mathrm{B}_{\mathrm{T}} / \mathrm{B}_{\mathrm{P}} \approx 0.12 \mathrm{kV} / \mathrm{m}$ for the corresponding NSST cases where the diameter of the $0.12 \mathrm{kV} / \mathrm{m}$ contour at $1 \mathrm{~s}$ is about $0.5 \mathrm{~m}$ which is similar to the DIII-D minor radius. The shape of the $\mathrm{E}_{\mathrm{T}} \cdot \mathrm{B}_{\mathrm{T}} / \mathrm{B}_{\mathrm{P}} \approx 0.12 \mathrm{kV} / \mathrm{m}$ contour remains essentially constant for over $10 \mathrm{~ms}$ with sufficient loop voltage of $\sim 7 \mathrm{~V}$. It is interesting to note that since the DIII-D and NSST have similar toroidal field $(\sim 2 \mathrm{~T})$ and major radius $(\sim 2 \mathrm{~m})$, the plasma start-up condition in NSST can be made remarkably similar to that of the DIII-D, giving some level of confidence in the present start-up method. Figure 11(c) shows that the flux is about $4.6 \mathrm{~Wb}$ at the time of the significant avalanche initiation which should be sufficient for the subsequent ramp up to a few MA. 


\section{DISCUSSIONS AND CONCLUSIONS}

An analysis for developing an out-board PF coil-only inductive start-up scheme was performed. A combination of three types of out-board PF coils placed outside the vacuum vessel is shown to create a good quality field null region while retaining significant volt-second capability for current ramp-up. For NSST, a high quality field null (multi-pole) can be created near $\mathrm{R}=2.5 \mathrm{~m}$ while the nearest Coil \#3 is placed at $\mathrm{R}=$ $3.1 \mathrm{~m}$ with adequate NBI/diagnostic access. Sufficient flux as large as about $4-5 \mathrm{~Wb}$ is available for ramping up the plasma current to a few MAs for the next generation ST devices such as NSST without using an OH solenoid. The concept should scale well to larger devices since the amount of flux tends to go up as square of the major radius. Once high plasma current is established ( $\geq 1 \mathrm{MA}$ ) to provide sufficient plasma confinement, it should be possible to use other means of non-inductive current drive such as the bootstrap over-drive, and/or NBI / RF current drive to further ramp up to full plasma current and maintain the current thus generated.

The PF coil system is relatively attractive from engineering point of view. It consists of relatively simple circular coils placed outside vacuum vessel so that the coil system can be made accessible. In addition, the maximum magnetic field at the coil is reasonable ( $\sim 15 \mathrm{~T}$ for the Coil \#1) for the NSST case generating about $5 \mathrm{~Wb}$. The Coil $\# 1$ is the highest stressed coil and therefore it must be designed accordingly. The Coil \#2 should be compatible with the capability needed for the vertical field required for the plasma equilibrium. The trim Coil \#3 is likely to be operated in a feedback mode for finer adjustments. The concept provides sufficient flexibility in the coil positions to accommodate the special needs of particular device configurations as several possible cases were shown. For a compact device such as CTF, one might consider the Case V configuration with about $1.8 \mathrm{~m}$ of vertical clearance at mid-plane to accommodate blanket modules. For a much larger ST power plant (e.g., ARIES-ST), the access is likely to be adequate for all cases considered. The number of coil set can be increased to further improve the field null configuration. The inherent limit of the flux value (voltsec) is likely to be imposed by the magnetic coil engineering limits and available power supplies. Since the present out-board ohmic coils are inherently pulsed for a relatively short duration, the coils are likely to be built with normal copper conductors perhaps 
cryogenically (nitrogen) cooled to reduce the power requirements. Through careful engineering design, it should be possible to further optimize the poloidal coil system to match the start-up requirements of a particular device.

The plasma stability with the presence of the eddy currents is an issue that will be further investigated in the future. Although the net vertical field outside the plasma helps radial plasma stability as mentioned above, an accurate equilibrium calculation will give the required amount of vertical and radial fields for proper force balance. The presence of the nearby passive stabilizers should aid the vertical stability, and additional small PF feed back coils can be used if necessary.

\section{ACKNOWLEDGEMENTS}

The authors would like to thank Drs. R. Goldston, R. Hawryluk, and M. Peng for their valuable comments and discussions. Thanks are also due to Drs. S. Jardin and C. Kessel for their support regarding the TSC code and valuable suggestions on numerical techniques.

\section{REFERENCES}

[1] PENG, M., HICKS, J. B., Fusion Technol. 2 (1991) 1990.

[2] PENG, M. et al., Fusion Engineering 2 (1998) 733; SVIATOSLAVSKY, I. V. et al., Fusion Eng. \& Design 45 (1999) 281.

[3] NAJMABADI, F. AND THE ARIES TEAM, Fusion Eng. \& Design 65 (2003) 143.

[4] NAJMABADI, F., JARDIN, S. C., TILLACK, M. S., WAGANER, L., AND THE ARIES TEAM, Proc. of 18th IAEA International Conference on Fusion Energy ( Sorrento, Italy, Oct. 2000$)$. http://www.iaea.org/programmes/ripc/physics/fec2000/html/node344.htm

[5] FOREST, C. B., et al., Phys. Plasmas 1 (1994) 1568. 
[6] SUZUKI, T., et al., in Fusion Energy 2002 (Proc. 19th Int. Conf. Lyon, 2002, EX/W2).

[7] FUJITA, T., et al., in Fusion Energy 2002 (Proc. 19th Int. Conf. Lyon, 2002, OV/1-3).

[8] JARBOE, T., et al, in Fusion Energy 2002 (Proc. 19th Int. Conf. Lyon, 2002) (Vienna: IAEA) CD-ROM file IC/P-10; RAMAN, R., et al., Phys. Rev. Lett. 90 (2003) 075005-1.

[9] SYKES, A., et al., Nucl. Fusion 41 (2001) 1423.

[10] MITARAI, O., Plasma Phys. Control. Fusion 41 (1999) 1469.

[11] MITARAI, O., TAKASE, Y., Fusion Sci. Technol. 43 (2003) 67.

[12] JARDIN, S., Nucl. Fusion 40 (2000) 1101.

[13] TAKASE, Y., et al., J. Plasma and Fusion Research 78 (2002) 719.

[14] KATSURAI, M., et al., "Overview of Compact Tori and Spherical Tokamak Researches with TS-3 and TS-4 Machines at University of Tokyo", Joint Meeting of the 3rd International Atomic Energy Agency Technical Committee Meeting on Spherical Tori and 8th International Spherical Torus Workshop, and US-Japan Workshop on Spherical Tokamak, PPPL, Princeton University, Princeton, NJ, U.S.A., 2002.

[15] ONO, M., CHOE, W., “Out-Board 'Ohmic Induction' Coil for Low-Aspect-Ratio Toroidal Plasma Start-up", Princeton University Patent Disclosure 03-2003-1.

[16] ONO, M., et al., "Design Innovations of the Next-Step Spherical Torus Experiment and Spherical Torus Development Path", Nucl. Fusion 44 (2004) 452.

[17] LLOYD, B., et al., Nucl. Fusion 31 (1991) 2031.

[18] PILLSBURY, Jr., R. D., et al., IEEE Trans. On Magnetics 28 (1992) 1462. 
[19] KIM, J., et al., "Simulation of Plasma Buildup in the Initial Phase of Inductive Outer PF Coil-only Start-up", Bull. American Physical Society Meeting 48, LP1-33, Albuquerque, NM (2003). 


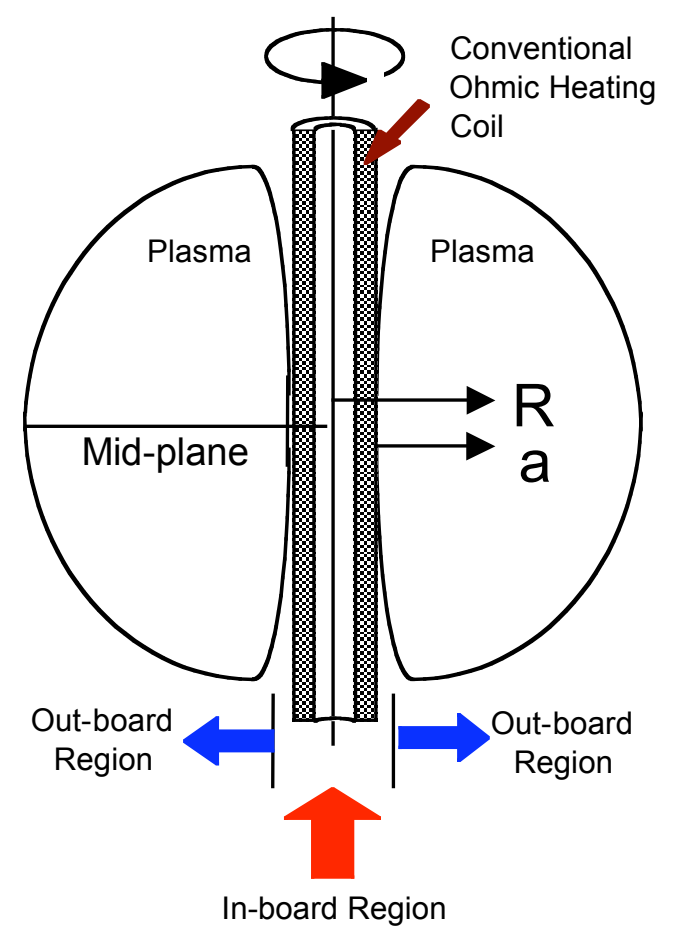

Fig. 1. A schematic depiction of the in-board and out-board regions. Location of a conventional solenoidal ohmic induction coil is also shown.

(a)

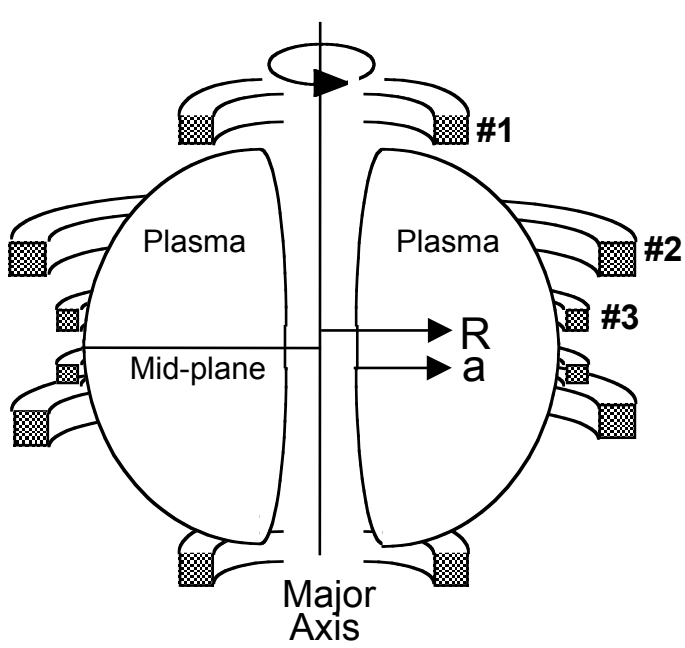

(b)

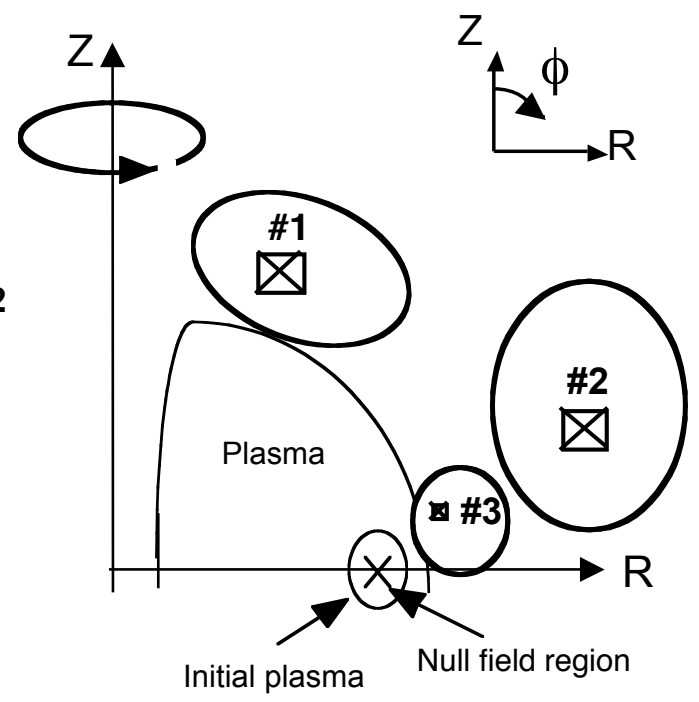

Fig. 2. (a) A schematic of the out-board ohmic induction coil system. (b) Out-board ohmic induction null formation and plasma initiation. Definition of the angle $\phi$ is also shown. 

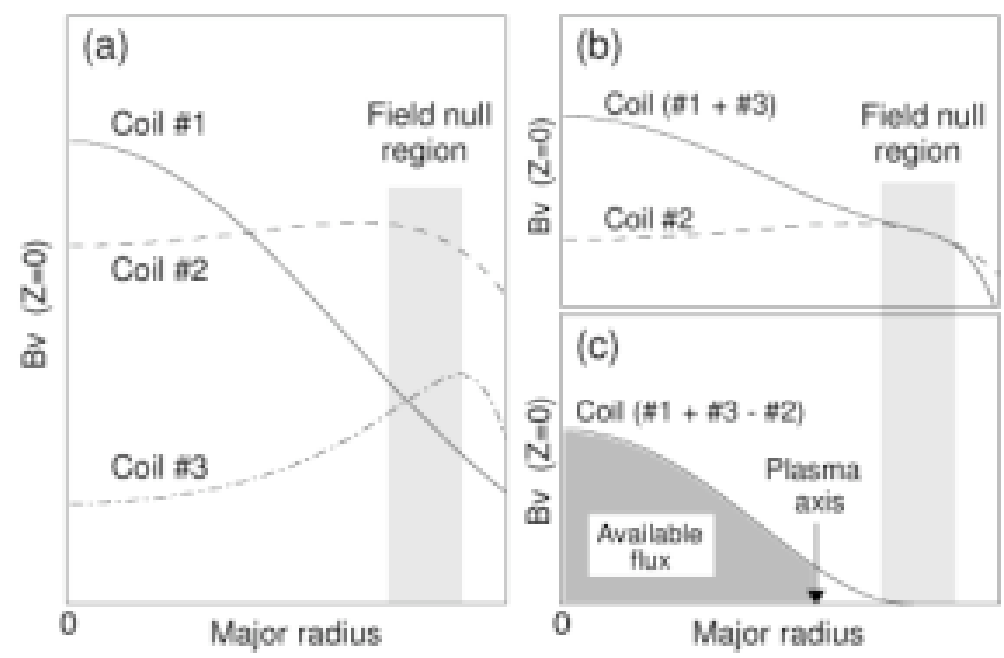

Fig. 3. (a) Vertical field profiles generated by Coils $\# 1, \# 2$, and \#3, as labeled. (b) Vertical field generated by a combination of Coils \#1 +\#3 and Coil \#2. (c) Net vertical field and the part contributing to the available magnetic flux at the expected plasma axis.

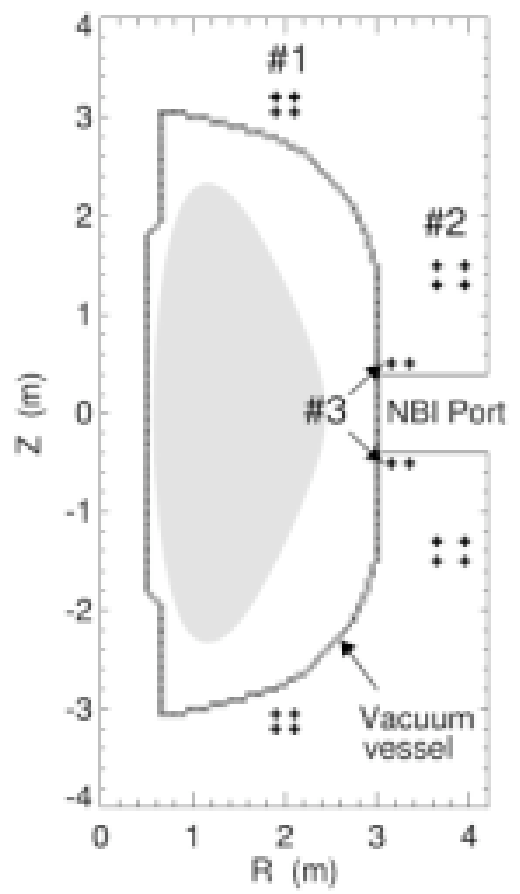

Fig. 4. An example of simulation setup using the NSST configuration. The shaded region inside the vacuum vessel represents a fully developed plasma for indicating its relative location from the coils. 
(a)

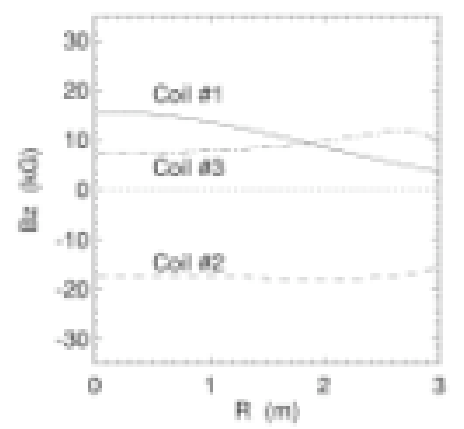

(d)

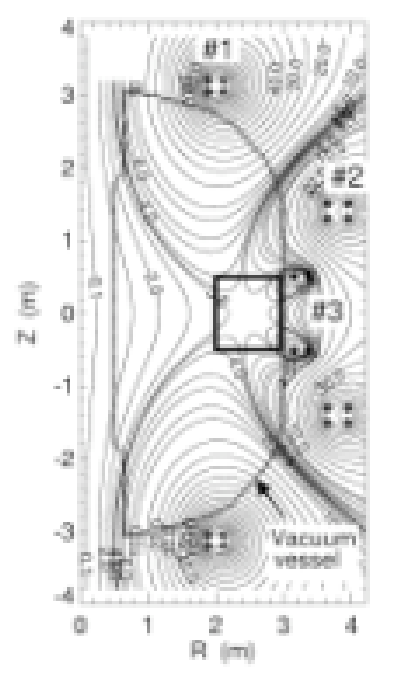

(b)

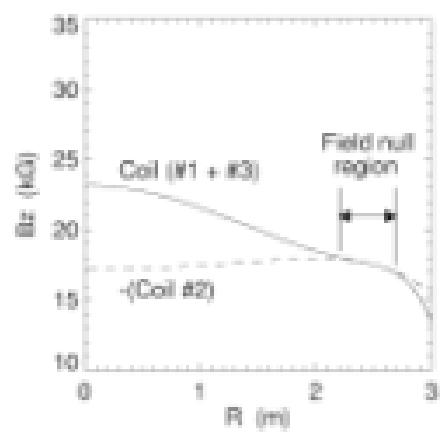

(e)

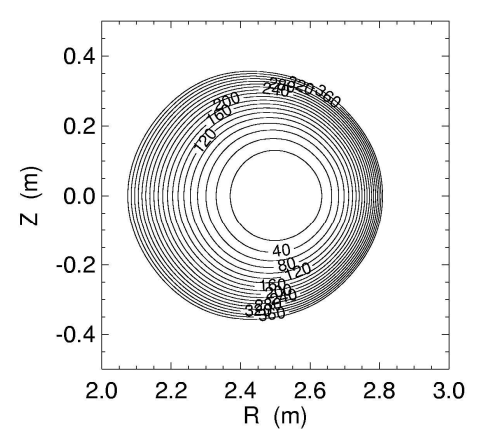

(c)

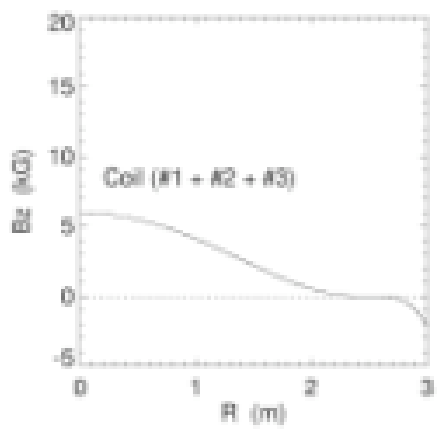

(f)

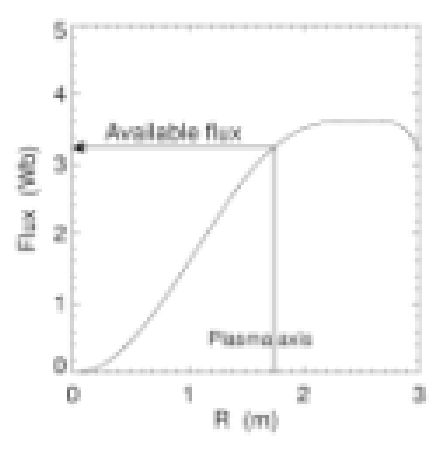

Fig. 5. Case I: Vertical field profiles and available flux on mid-plane generated by Coils $\# 1, \# 2$, and $\# 3$, as labeled. (a) Vertical field generated by the individual coil. (b) Vertical field generated by a combination of Coil \#1 and \#3 compared to Coil \#2. The Coil \#2 current is multiplied by $(-1)$ for easy comparison. (c) The net vertical field profile from all three coil sets. (d) 2-D flux contours. (e) Mod-B contours of the field null region. The region of less than $20 \mathrm{G}$ of $20 \mathrm{~cm}$ diameter is created around $\mathrm{R}=2.5 \mathrm{~m}$. (f) The magnetic flux available as a function of major radius. 

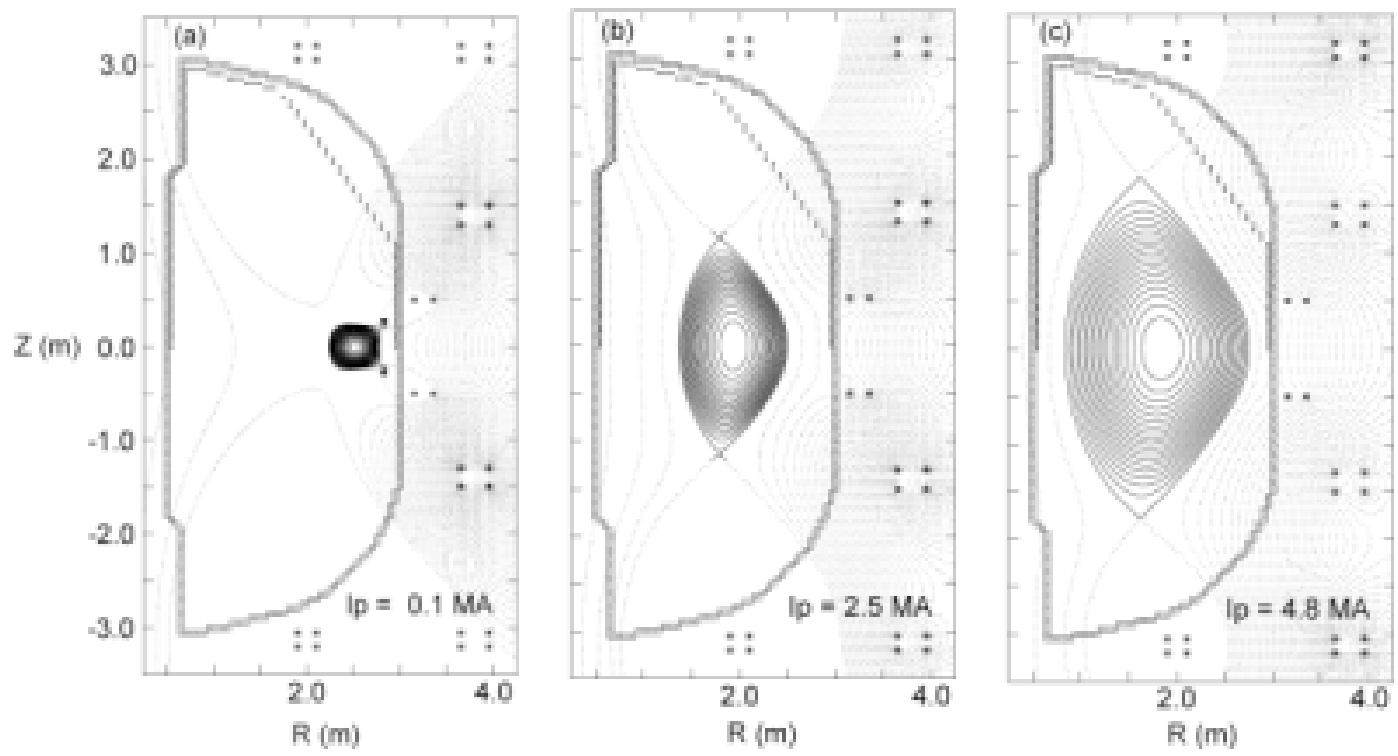

Fig. 6. Plasma equilibrium for various values of plasma current, as labeled.

(a)

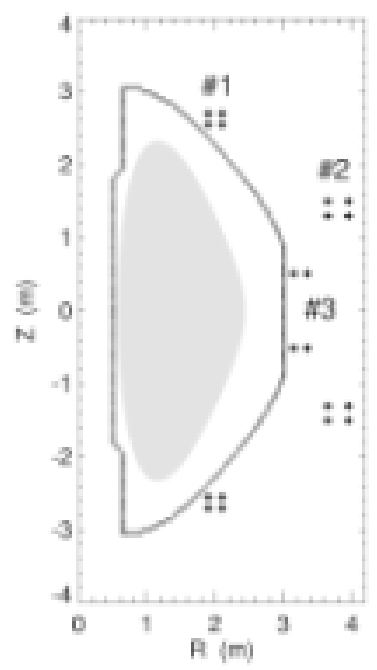

(b)

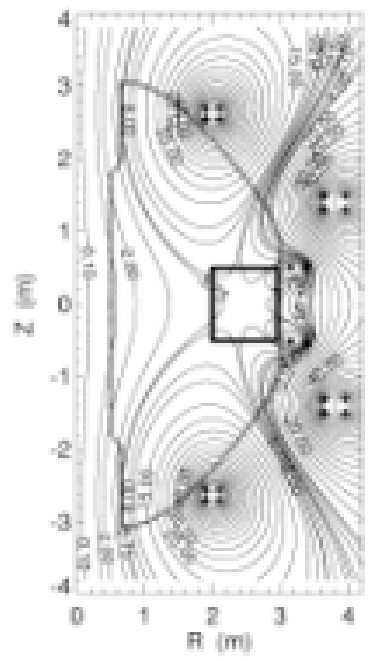

(c)

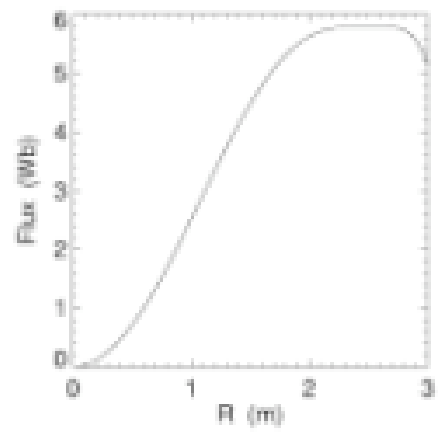

Fig. 7. Case II: Coil \#1 lowered for offering more flux. The vacuum vessel is contoured accordingly. 
(a)

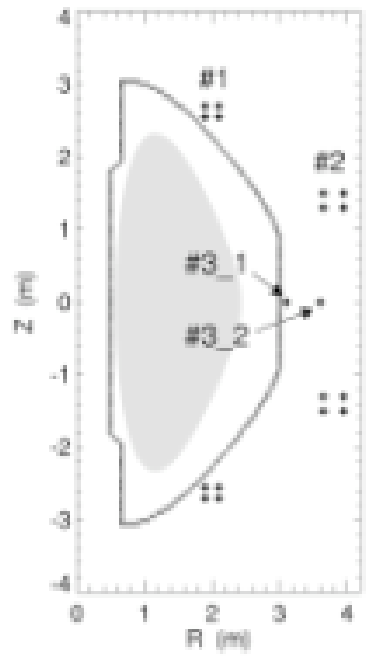

(d)

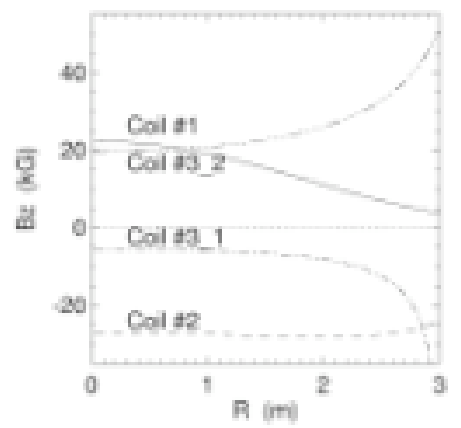

(b)

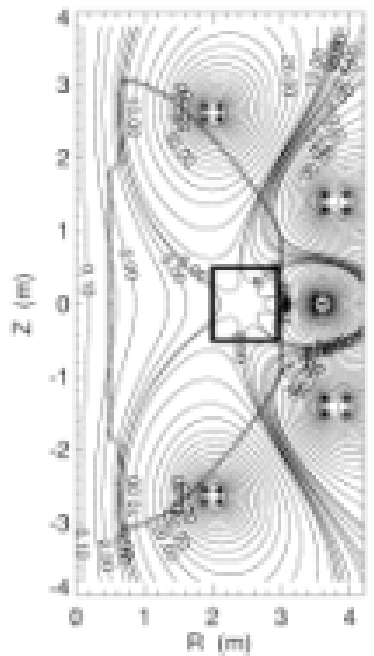

(e)

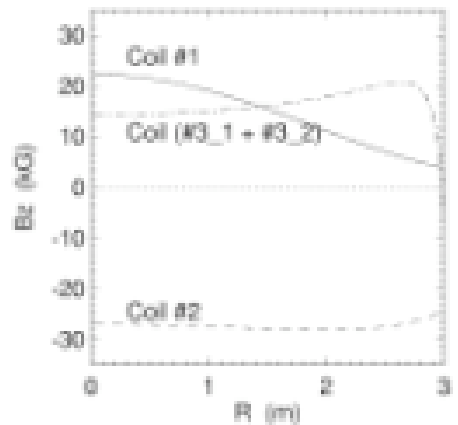

(c)

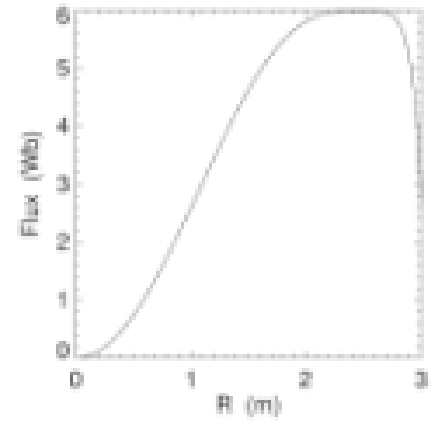

(f)

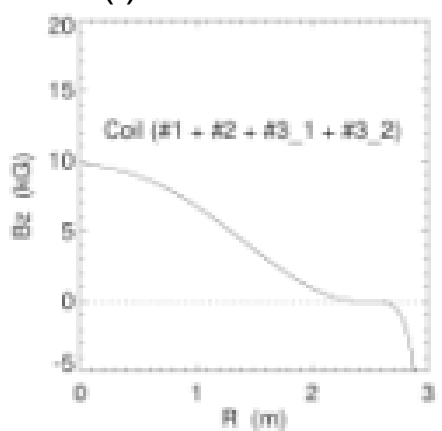

Fig. 8. Case III: Coil \#3 located on mid-plane for the capability of accommodating blankets. 
(a)

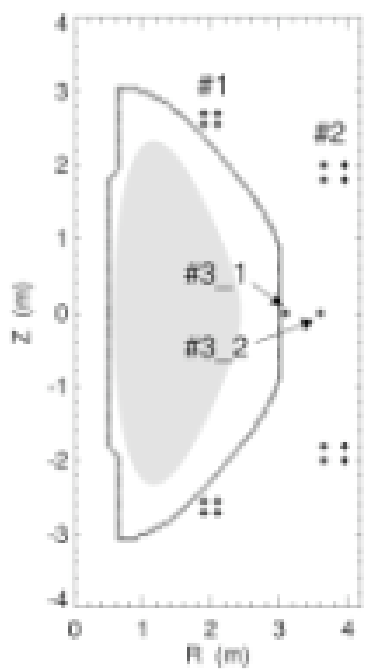

(b)

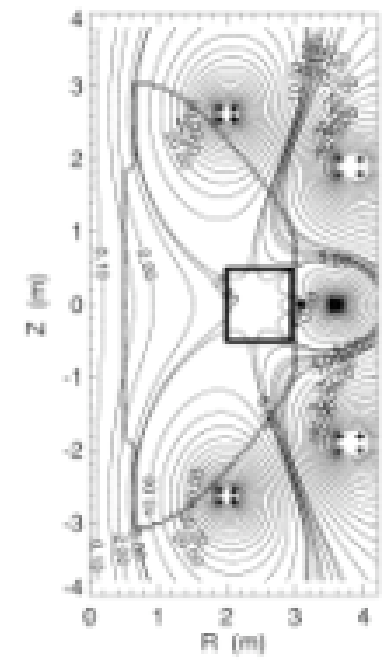

(c)

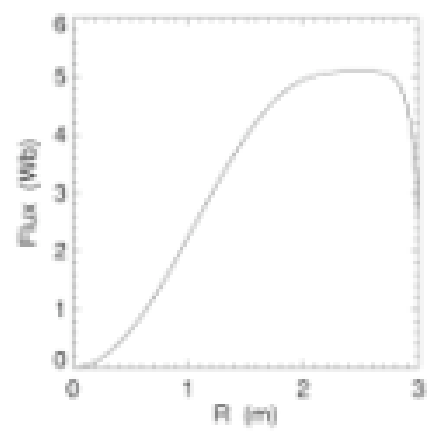

Fig. 9. Case IV: Coil \#3 placed on mid-plane and separation between up and down Coil \#2 increased further to provide additional space for the blanket access. 
(a)

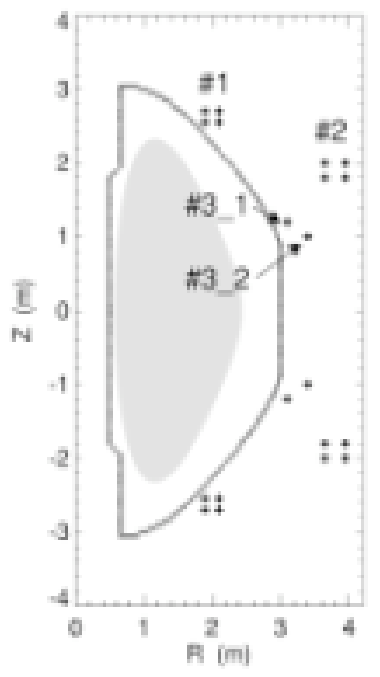

(e)

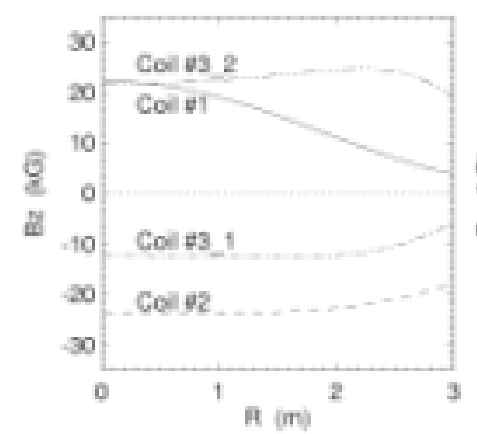

(b)

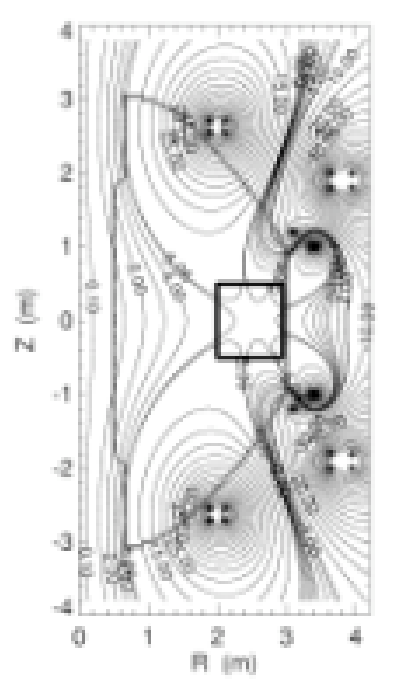

(f)

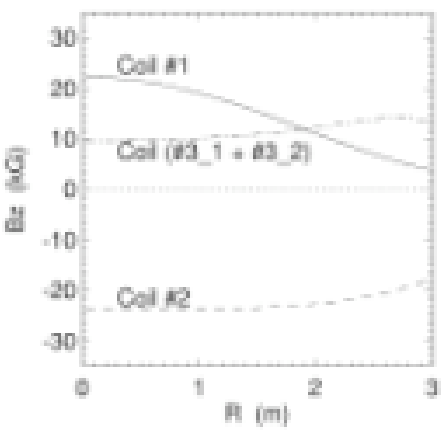

(c)

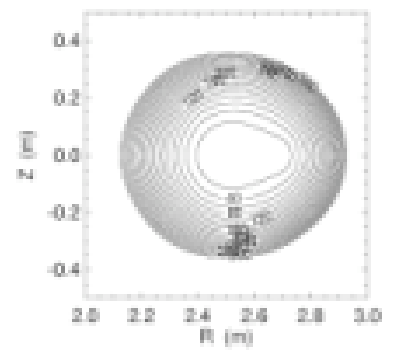

(d)

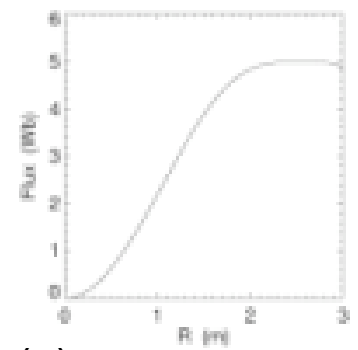

(g)

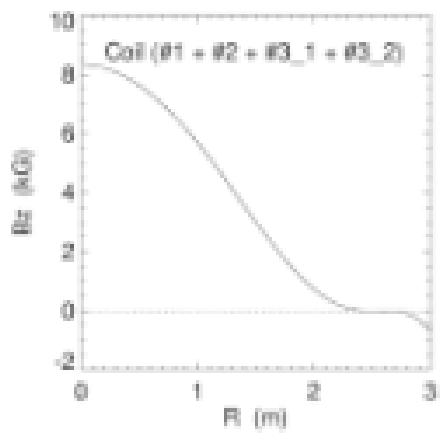

Fig. 10. Case V: Field geometry similar to Fig. 9 can be obtained by using two pairs of the up-down Coil \#3_1 and \#3_2. 
(a)

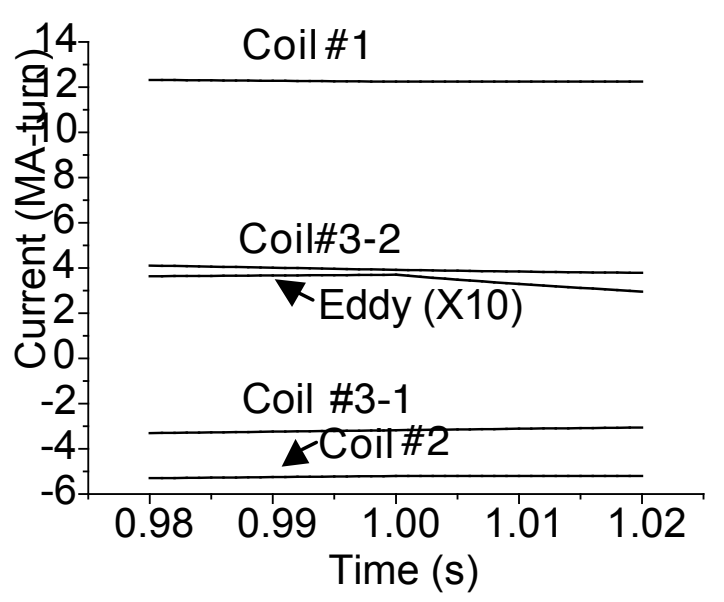

(c)

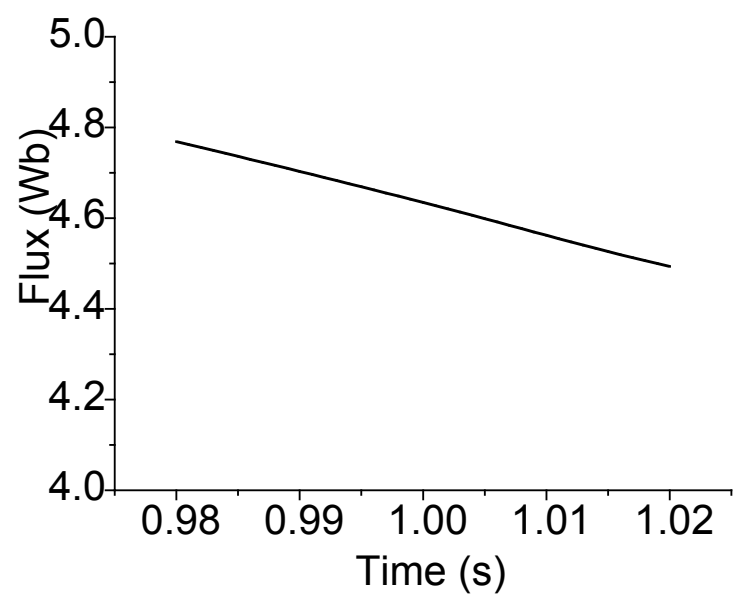

(b)

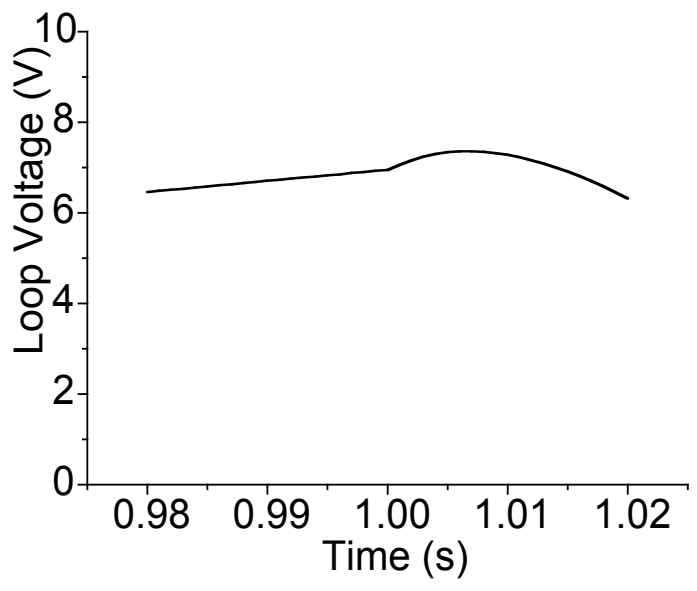

(d)

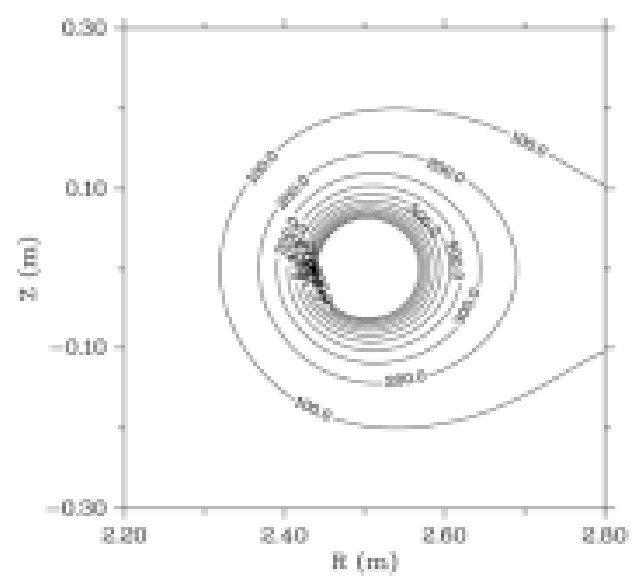

Fig. 11. An example of the time-dependent calculation for Case $\mathrm{V}$ in consideration of vacuum vessel eddy currents. (a) Current waveform of the individual coil and the total eddy current, (b) the corresponding loop voltage, and (c) the magnetic flux at $\mathrm{R}=2.5 \mathrm{~m}$. The eddy current was multiplied by 10 for comparison. (d) Contours of $\mathrm{E}_{\mathrm{T}} \cdot \mathrm{B}_{\mathrm{T}} / \mathrm{B}_{\mathrm{P}}$ in $\mathrm{V} / \mathrm{m}$ at $1 \mathrm{~s}$. The shape of the contours remains almost unchanged for more than $10 \mathrm{~ms}$. Force balance or equilibrium of the initial plasma was not considered. 


\begin{tabular}{|c|c|c|c|c|c|c|}
\hline & & Case I & Case II & Case III & Case IV & Case V \\
\hline \multirow{3}{*}{ Coil \#1 } & $\mathrm{R}(\mathrm{m})$ & 2.00 & 2.00 & 2.00 & 2.00 & 2.00 \\
\hline & $\mathrm{Z}(\mathrm{m})$ & \pm 3.12 & \pm 2.63 & \pm 2.63 & \pm 2.63 & \pm 2.63 \\
\hline & I (kA-turn) & $+16,000$ & $+16,000$ & $+16,000$ & $+16,000$ & $+16,000$ \\
\hline \multirow{3}{*}{ Coil \#2 } & $\mathrm{R}(\mathrm{m})$ & 3.80 & 3.80 & 3.80 & 3.80 & 3.80 \\
\hline & $Z(m)$ & \pm 1.40 & \pm 1.40 & \pm 1.40 & \pm 1.90 & \pm 1.90 \\
\hline & I (kA-turn) & $-6,290$ & $-8,975$ & $-9,802$ & $-10,006$ & $-10,006$ \\
\hline \multirow{3}{*}{$\begin{array}{c}\text { Coil \#3 } \\
\text { (or Coil \#3_1) }\end{array}$} & $\mathrm{R}(\mathrm{m})$ & 3.25 & 3.25 & 3.10 & 3.10 & 3.10 \\
\hline & $Z(m)$ & \pm 0.51 & \pm 0.51 & 0.00 & 0.00 & \pm 1.20 \\
\hline & I (kA-turn) & $+1,994$ & $+3,114$ & $-1,299$ & -944.0 & $-3,689$ \\
\hline \multirow{3}{*}{ Coil \#3_2 } & $\mathrm{R}(\mathrm{m})$ & - & - & 3.60 & 3.60 & 3.40 \\
\hline & $Z(m)$ & - & - & 0.00 & 0.00 & \pm 1.00 \\
\hline & I (kA-turn) & - & - & $+5,561$ & $+3,899$ & $+6,670$ \\
\hline $\begin{array}{c}\text { Flux } \\
\text { (at } R=1.75 \mathrm{~m})\end{array}$ & $\Psi(\mathrm{Wb})$ & 3.25 & 5.20 & 5.97 & 4.60 & 4.50 \\
\hline
\end{tabular}

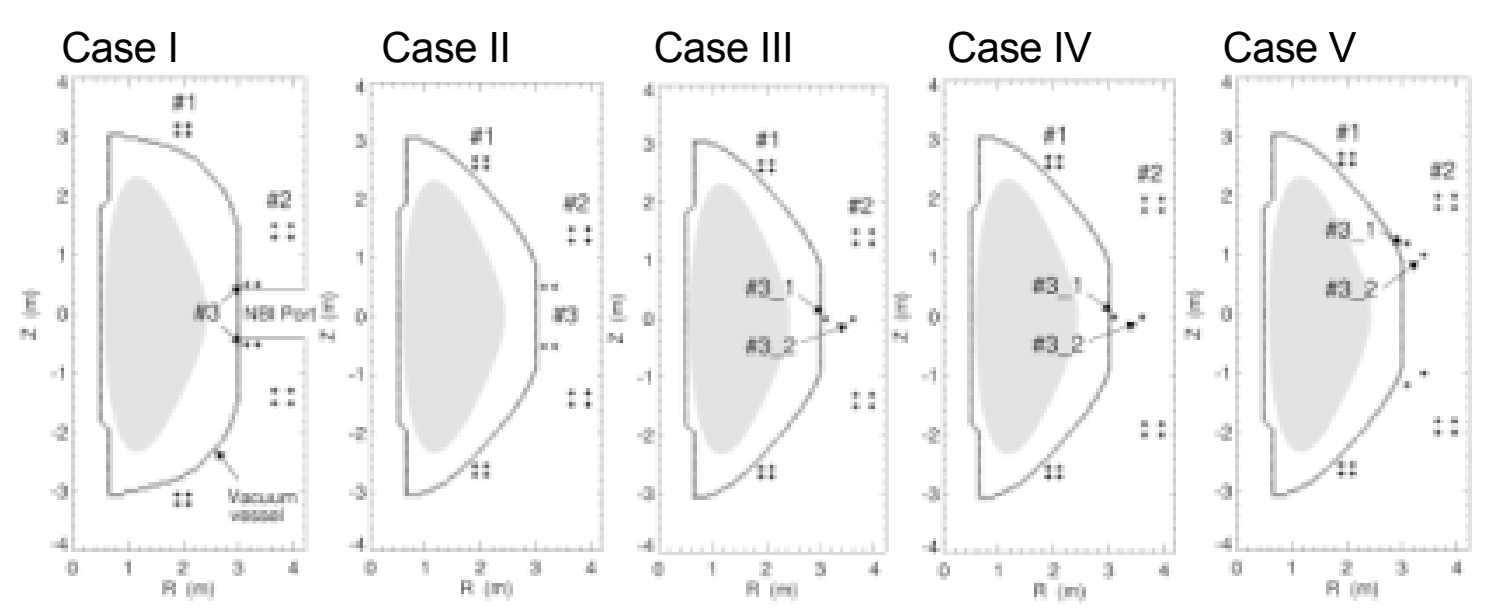

Table 1. Position and current of the individual PF coil for five different cases considered. The magnetic flux at the expected plasma center is also given. 


\section{External Distribution}

Plasma Research Laboratory, Australian National University, Australia

Professor I.R. Jones, Flinders University, Australia

Professor João Canalle, Instituto de Fisica DEQ/IF - UERJ, Brazil

Mr. Gerson O. Ludwig, Instituto Nacional de Pesquisas, Brazil

Dr. P.H. Sakanaka, Instituto Fisica, Brazil

The Librarian, Culham Laboratory, England

Mrs. S.A. Hutchinson, JET Library, England

Professor M.N. Bussac, Ecole Polytechnique, France

Librarian, Max-Planck-Institut für Plasmaphysik, Germany

Jolan Moldvai, Reports Library, Hungarian Academy of Sciences, Central Research Institute for Physics, Hungary

Dr. P. Kaw, Institute for Plasma Research, India

Ms. P.J. Pathak, Librarian, Institute for Plasma Research, India

Ms. Clelia De Palo, Associazione EURATOM-ENEA, Italy

Dr. G. Grosso, Instituto di Fisica del Plasma, Italy

Librarian, Naka Fusion Research Establishment, JAERI, Japan

Library, Laboratory for Complex Energy Processes, Institute for Advanced Study, Kyoto University, Japan

Research Information Center, National Institute for Fusion Science, Japan

Dr. O. Mitarai, Kyushu Tokai University, Japan

Dr. Jiangang Li, Institute of Plasma Physics, Chinese Academy of Sciences, People's Republic of China

Professor Yuping Huo, School of Physical Science and Technology, People's Republic of China

Library, Academia Sinica, Institute of Plasma Physics, People's Republic of China

Librarian, Institute of Physics, Chinese Academy of Sciences, People's Republic of China

Dr. S. Mirnov, TRINITI, Troitsk, Russian Federation, Russia

Dr. V.S. Strelkov, Kurchatov Institute, Russian Federation, Russia

Professor Peter Lukac, Katedra Fyziky Plazmy MFF UK, Mlynska dolina F-2, Komenskeho Univerzita, SK-842 15 Bratislava, Slovakia

Dr. G.S. Lee, Korea Basic Science Institute, South Korea

Institute for Plasma Research, University of Maryland, USA

Librarian, Fusion Energy Division, Oak Ridge National Laboratory, USA

Librarian, Institute of Fusion Studies, University of Texas, USA

Librarian, Magnetic Fusion Program, Lawrence Livermore National Laboratory, USA

Library, General Atomics, USA

Plasma Physics Group, Fusion Energy Research Program, University of California at San Diego, USA

Plasma Physics Library, Columbia University, USA

Alkesh Punjabi, Center for Fusion Research and Training, Hampton University, USA

Dr. W.M. Stacey, Fusion Research Center, Georgia Institute of Technology, USA

Dr. John Willis, U.S. Department of Energy, Office of Fusion Energy Sciences, USA

Mr. Paul H. Wright, Indianapolis, Indiana, USA 
The Princeton Plasma Physics Laboratory is operated by Princeton University under contract with the U.S. Department of Energy.

\author{
Information Services \\ Princeton Plasma Physics Laboratory \\ P.O. Box 451 \\ Princeton, NJ 08543
}

Phone: 609-243-2750

Fax: 609-243-2751

e-mail: pppl_info@pppl.gov

Internet Address: http://www.pppl.gov 